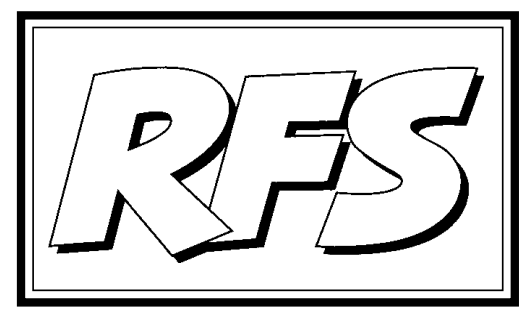

Revista de Fomento Social, 57 (2002), 725-731

\title{
XV Reunión del Grupo Fomento Social
}

(Córdoba, 23-24 noviembre 2002)

IIdefonso CAMACHO LARAÑA S. J .

Este año el Grupo Fomento Social, formado por jesuitas que se ocupan en temas sociales, trasladó el lugar de su encuentro: se fue de Madrid, lugar normal de sus reuniones, a la sierra cordobesa (a la recién remodelada Casa de Espiritualidad de San Antonio). Allí se encontraron 36 jesuitas y 11 laicos (éstos últimos, procedentes de instituciones universitarias de la Compañía de J esús o de ONG vinculadas a ella).

El tema central de la reunión fue: “La cooperación al desarrollo en el marco de la globalización". La ponencia marco fue introducida por José Juan Romero, Profesor de ETEA (Córdoba), con un "breve enmarque de la cooperación al desarrollo en la misión de la Compañía", y desarrollada en su parte más extensa por Pedro Caldentey del Pozo, también Profesor de ETEA y encargado de las Relaciones Internacionales en esta institución. El encuentro se completó con la presentación de experiencias relacionadas con la cooperación al desarrollo: concretamente lo que hacen en este campo las instituciones universitarias y las ONG antes citadas. 
Al comienzo de las sesiones se tuvo un recuerdo especial para Federico González-Fierro Botas, miembro del Grupo y asiduo participante en sus encuentros, que falleció este verano en Rusia como consecuencia de un accidente de automóvil. Cada año viajaba a aquel país para impartir cursos y colaborar con los jesuitas que trabajan allí.

\section{El tema de fondo: "La cooperación al desarrollo en el marco de la globalización"}

La primera parte de la ponencia tenía carácter como de una meditación preparatoria. Partía de la parábola evangélica del rico comilón y el pobre Lázaro, como símbolo del abismo de la desigualdad existente en nuestro mundo, para recoger luego algunos elementos de la tradición ignaciana y jesuítica. Si queremos una globalización no excluyente sino integradora, la Compañía puede poner al servicio de esta causa su carácter internacional, que lo caracterizó desde sus orígenes. Su última Congregación General ha recordado las posibilidades que encierra el hecho de que la Compañía esté presente en muchos países del mundo. Finalmente se subrayó la actitud desdela que hay que hacer cooperación internacional: en solidaridad con los más necesitados. Dos breves citas de esta última Congregación General lo ilustran:

\footnotetext{
"Ignacio y sus seguidores comenzaron su predicación en pobreza. Trabajaron con los poderosos y los sin poder, con príncipes, reyes y obispos, pero también con las mujeres de la calle y con las víctimas de la peste. Conectaron su ministerio con los poderosos a las necesidades de los sin poder.

Hoy en día, sea cual sea nuestro ministerio, nos hacemos solidarios con los pobres, los marginados y los sin voz, para que puedan participar en los procesos que modelan la sociedad en la que todos vivimos y trabajamos. Ellos a su vez nos instruyen acerca de nuestra pobreza como ningún documento podría hacerlo. Nos ayudan a entender el sentido de la gratuidad de nuestros ministerios, a dar gratis lo que gratis hemos recibido, a dar nuestras mismas vidas. Nos muestran el modo de inculturar los valores del Evangelio en situaciones donde Dios está olvidado. A través de esta solidaridad llegamos a ser agentes de inculturación" ${ }^{1}$.
}

El contenido fundamental de la segunda parte de la ponencia se centró en presentar y comentar los principales debates abiertos hoy en torno a la cooperación, distinguiendo los debates generales de aquellos que se refieren específicamentea la cooperación oficial o a la cooperación no gubernamental.

1 Congregación General 34 de la Compañía de J esús, Decreto 26 ("Características de nuestro modo de proceder"), nn. 13 y 15. 
Los debates generales sobre la cooperación hoy se sitúan en torno a una cierta crisis de la misma cooperación. Pero ¿es crisis de la cooperación o es, más bien, crisis del mismo desarrollo? Porque los esfuerzos en pro de la cooperación no se traducen en un verdadero desarrollo sostenido de los beneficiarios de aquella. Esto permite hablar de "la fatiga del donante", ante la falta de resultados. Objeto de debate es también el llamado "consenso de Washington", que ha logrado la estabilidad económica de esos pueblos, pero no ha resuelto los otros problemas. Todo esto nos sitúa ante la necesidad de reelaborar el concepto de desarrollo aprovechando elementos de los aportados por las diferentes escuelas: neoliberales, neoestructuralistas y alternativos (y aquí podrían situarse los informes del PNUD). En todo caso, estamos en un momento de evaluación de una historia rica en propuestas e iniciativas pero no tan rica en resultados.

La cooperación oficial también ha dado lugar a importantes debates. El "Seattle People" puede ser expresión de ellos. O lo que otros han Ilamado "la esperanza de Porto Alegre" con sus propuestas frente al ALCA (Área de Libre Comercio de las Américas). La crisis de las instituciones multilaterales es objeto también de análisis y nuevas propuestas. Y siempre son recurrentes la condicionalidad de la ayuda (aunque puede hablarse de una "condicionalidad buena", por ejemplo cuando está en relación con la condonación de la deuda externa), las ayudas ligadas (práctica tan utilizada por España), los criterios para establecer prioridades sectoriales y geográficas, la coherencia de las políticas (¿no deshacemos por otro lado lo que hacemos a través de la cooperación?) y la nueva dependencia (cuando la cooperación es distorsión más que ayuda y termina generando más dependencia).

Tampoco la cooperación no gubernamental está libre de debates. No hay que tener miedo a "manchar a los ángeles". Porque no todo vale en esta cooperación. Habría que empezar por cuestionar a muchas ONGD y su competencia para hacer lo que están haciendo. Hay que denunciar también cierta "proyectitis", o ese afán de trabajar en función de los proyectos, de sus condiciones en cuanto a duración, financiación, etc. Dichas condiciones obligan muchas veces a empequeñecer los proyectos. Por eso, entre otras razones, abundan los pequeños proyectos. Y la proliferación de estos conlleva el riesgo de fragmentar el trabajo y desarticular las sociedades. También en este campo estamos muy necesitados de una autoevaluación.

Como conclusión de todo esto, el ponente expresó su convicción de que hace falta "más desarrollo y menos cooperación", porque lo que está ocu- 
rriendo en la práctica es precisamente lo contrario: insistimos más en la cooperación que en el desarrollo, que es lo único que daría autonomía a los pueblos y esperanza ante el futuro.

A modo de complemento, Pedro Caldentey ofreció una presentación de lo que viene realizando ETEA en el campo de la cooperación al desarrollo. Destacó los tres principios que la inspiran en cuanto institución universitaria: la formación de capital humano, la ayuda para construir universidad, la presencia de la cooperación en el día a día de la propia ETEA (como elemento fecundante de toda su actividad). Entre las acciones realizadas distinguió las de primera generación (diagnóstico de la realidad, formación de formadores y apoyo a la gestión universitaria) de las de segunda generación (proyectos de cooperación y apoyo a las políticas públicas). Esta distinción permite comprender que la dinámica de la cooperación debe orientarse a eliminar toda dependencia y a dotar a sus beneficiarios de una auténtica autonomía en su desarrollo.

A la ponencia siguió un extenso diálogo, que se prolongó a lo largo de toda la mañana. Los temas fueron variados, reflejando la variedad de ocupaciones y experiencias de los participantes. Quizás destacó sobre todos el papel del Estado de los países en vías de desarrollo: la necesidad de que éste asuma el protagonismo que le corresponde, pero también las limitaciones que encuentra por su propia estructura y por la corrupción que muchas veces le invade. Cuestión no menos importante fue el papel de las ONG en todos estos procesos, y no sólo en su actividad en aquellos países a los que se dirigen, sino también en los nuestros, dejando sentir su influencia sobre los gobiernos y sobre la sociedad en general. El hecho de las migraciones estuvo igualmente presente en las intervenciones de algunos, insistiendo en la necesidad de vincular este problema con las políticas de cooperación. Y como preocupación siempre latente muchos se preguntaban y reflexionaban sobre las posibilidades y dificultades de la Compañía de Jesús y de sus instituciones para participar de forma positiva en todo este campo.

\section{La acción de los centros universitarios y ONG vinculados a la Compañía de J esús}

La sesión de la tarde fue complementaria de la de la mañana. Diversas instituciones vinculadas a la Compañía de J esús presentaron sus actividades en el campo de la cooperación. La sesión se dividió en dos partes. En primer lugar desfilaron las ONG que tienen alguna relación con la Compañía: 
concretamente lo hicieron Alboan (presentada por Marlen Eizaguirre), Entreculturas (Agustín Alonso y Luis Arancibia) e Intermón-Oxfam (Gonzalo Fanjul y José Antonio Hernández del Toro). Su intervención no estuvo prioritariamente centrada en exponer todo lo que hacían; más bien se detuvieron en los presupuestos desde los que enfocaban la cooperación y en las sinergias que encontraban con la Compañía de J esús y sus instituciones.

La segunda parte dela tardela ocuparon los centros universitarios jesuitas de España. Intervinieron J uan Carlos Duque por la Universidad de Deusto, Andrés González García por la Universidad Pontificia Comillas y Josep Miralles por ESADE. A propósito de estas presentaciones se suscitaron algunos temas de debate. Ante todo, la necesidad de distinguir la cooperación al desarrollo estrictamente tal de otras formas de colaboración entre universidades. A este respecto insistían algunos en la necesidad de clarificar el concepto mismo de cooperación y recordaban que la ponencia de la mañana había ofrecido no pocos elementos para ello. También se debatió si la cooperación debería ser onerosa para los centros, de forma que éstos contribuyeran con recursos propios, al menos en parte, a la financiación de sus proyectos: algunos aducían el ejemplo de algunas instituciones que aportaban el $0,7 \%$ de su presupuesto para cooperación al desarrollo.

Todavía hubo tiempo en la tarde para hacer una breve presentación del Banco de Recursos, que funciona en Barcelona. Se define a sí mismo como una ONG de servicios, cuyo objetivo es la distribución de recursos, sobre todo de aquellos excedentes que proceden de las empresas. Aunque es una ONG relativamente joven y muy especializada, está en un proceso de clara expansión.

\section{Otras informaciones}

La mañana del domingo 24 fue de contenidos variados: una parte fue ocupada por diversas informaciones, fuera ya del ámbito de la cooperación, mientras que la parte final se dedicó a la asamblea estatutaria del Grupo Fomento Social.

Informó en primer lugar J aime Oráa sobre el próximo congreso de Eurojess (jesuitas europeos de ciencias sociales). Describió cómo se ha preparado el congreso, que se celebrará del 23 al 30 de agosto de 2003 en Hungría. El tema será las relaciones Este-Oeste en Europa. Como cuestiones a abordar en el mismo se señalan las siguientes: pobreza y marginación en Europa, amplia- 
ción de la Unión Europea, diferencias culturales, derechos de las minorías, nacionalismos e identidad europea.

En segundo lugar informó Alfonso Álvarez Bolado sobre la XI Semana de Formación Política que se celebrará, como se viene haciendo hasta ahora, en Salamanca en julio de 2003. Es característico de estas semanas el poner la iniciación política en relación con la espiritualidad ignaciana. Se alternan los contenidos: un año se da un curso de iniciación y otro se aborda un tema monográfico. La próxima edición toca el enfoque monográfico. Se dedicará concretamente a las alternativas al neoliberalismo.

La tercera intervención informativa corrió a cargo de Fernando Franco, que acaba de ser nombrado Director del Secretariado Social de la Compañía de Jesús (en Roma) en sustitución de Michael Czerny, que tantas veces nos acompañó en años precedentes en este encuentro. Aunque español de nacimiento, su vida jesuítica se ha desarrollado casi totalmente en la India. Ahora llega a ocupar este nuevo puesto con el encargo inmediato de hacer una evaluación del apostolado social en la Compañía. Para ello se convocará una reunión de los coordinadores del apostolado social en los distintos continentes y regiones, que tendrá lugar en Roma del 6 al 12 de abril de 2003. Aprovechó también la oportunidad para ofrecer sus reflexiones sobre la Cumbre de J ohannesburgo, de agosto de este año. Él formó parte del equipo de jesuitas que asistió a la Cumbre convocada por Naciones Unidas. Transmitió las conclusiones que él extraía del evento: el papel de los distintos organismos internacionales y el peso de la Organización Mundial del Comercio, la importancia de los nuevos modelos organizativos para trabajar en red a este nivel, la esperanza que se alumbra en otros foros alternativos (como el Foro Social de Florencia).

\section{El Grupo Fomento Social y el apostolado social de la Compañía de J esús en España}

Como en otras ocasiones se dedicó un tiempo a reflexionar sobre el apostolado social de la Compañía de Jesús en España y Portugal. Este año había una novedad. El Provincial del España ha nombrado un Delegado suyo para la coordinación de todo este sector social en España en la persona de Darío Mollá, Provincial de Aragón. Fue ésteúltimo quien presentó la actividad de la Comisión Interprovincial de Acción Social desde el encuentro que se celebró en Alcalá de Henares en diciembre de 2000. Fue entonces cuando se 
señalaron tres líneas prioritarias, que ha sido objeto de coordinación y estímulo a nivel nacional desde entonces. Dichas líneas son: migraciones, adolescentes y jóvenes en riesgo, cooperación internacional. El funcionamiento en cada uno de estos ámbitos es diferente, dependiendo de lo que ya se hace en las distintas Provincias jesuitas de España y de las necesidades de los que trabajan en esos campos.

Al hablar de las relaciones entre la Comisión que él preside y el Grupo Fomento Social, se reafirmó en la conclusión de años anteriores: este Grupo debe seguir siendo lo que es, un foro de encuentro e intercambio entre jesuitas y, cada vez más, laicos que trabajan en instituciones de la Compañía. Pero también expresó su interés de que el Grupo Fomento Social estuviera presente en todo el proceso de reestructuración y revitalización de la Comisión Interprovincial.

\section{Conclusión}

En encuentro terminó con la asamblea estatutaria del Grupo. En ella se procedió a evaluar la sesión de este año. Se destacó la riqueza derivada de la presencia de personas de distintas instituciones, todas ellas con experiencia en el tema central del encuentro; se valoró también positivamente la asistencia de laicos. El no tener necesidad de llegar a unas conclusiones da mayor libertad a los debates y permite insistir más en el encuentro e intercambio entre los reunidos.

Respecto al próximo encuentro, se decidió que se celebrara en Madrid. Como tema se propusieron dos, que obtuvieron un número igual de adhesiones por parte de los participantes: "África, continente olvidado" y "Sociedad civil, participación y ciudadanía". 